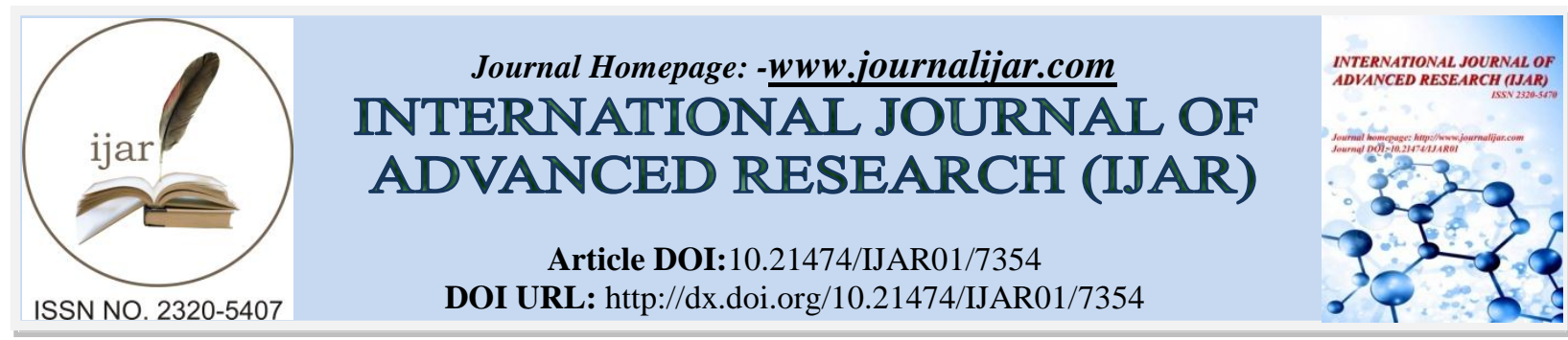

RESEARCH ARTICLE

\title{
QUALITY OF LIFE OF MOTHERS OF CHILDREN WITH LEUKEMIA.
}

1. M.Sc (N), College of Nursing, JIPMER.

Saranya. $K^{1}$ and Dr. P. Vetriselvi ${ }^{2}$.

2. Assistant Professor, College of Nursing, JIPMER.

\section{Manuscript Info}

Manuscript History

Received: 05 May 2018

Final Accepted: 07 June 2018

Published: July 2018

\begin{abstract}
Diagnosis of leukemia in children affects the parents more than the children. Their activities of daily living is affected and thus inturn affects the quality of life of parents especially mothers, who are the primary caregivers of the children. Thus, a cross sectional study was conducted to evaluate the quality of life of mothers of children with leukemia. A standardized tool was used. Total sample was 73. According to the results, the overall mean scores of quality of life of mothers of children with leukemia was 77.03 and there was no significant association between the quality of life and mothers of children with leukemia and socio demographic variables.
\end{abstract}

Copy Right, IJAR, 2018,. All rights reserved.

\section{Introduction:-}

Health is the primary factor In the actualization of human potential. Health is defined by WHO as " a state of complete physical, mental and Social well - being of an individual and not merely the absence of disease or infirmity". From this definition, it is clear that health is multidimensional. Health is attaining with the help of different components, and efforts and it should begin at individual level.

The future of the society is based on the health of the children. The child is to survive; the society must make provisions for their care and nurture. Today's children are the tomorrow's future who is going to become the full-fledged members of the community. Children are more sensitive to disease, so they need particular care and protection. Childhood cancer is a flagrant and heart-rending situation in India. Every one out of 600 children suffers from childhood cancer. Leukemia accounts for $33 \%$ of all childhood cancer. The concept of quality of life is considered as one's perception of her/his welfare which originates from his/her current life experience. Since long-term treatment is painful and invasive, it will affect the quality of life of mothers of children with leukemia. Hence, this study undertaken with the objective to assess their quality of life.

\section{Materials and Methods:-}

A descriptive design is used for this study.

\section{Inclusion Criteria:-}

Mothers of children with leukemia.

1. In the age group of 1 to 18 years, attending cancer clinic in JIPMER. 
2. With Acute Lymphoblastic leukemia (ALL) or Acute Myeloid Leukemia.

3. Who can communicate in Tamil or English.

\section{Exclusion Criteria:-}

Mothers of children who are critically ill with

1. Severe anemia

2. Infection

3. Bleeding.

Method of sample selection:-

Convenience sampling technique was used to select the study sample.

\section{Instruments:-}

Subject data sheet had a set of questions that was oriented to the demographic and clinical data. To assess the quality of life, pediatric quality of life inventory, which is a standardized tool was used.

\section{Data Collection Procedure:-}

Researcher introduced herself to the participants, and a written informed consent obtained. Subject data sheet information and quality of life data were collected by the investigator through structured interview schedule.

\section{Ethical Considerations:-}

Informed consent taken from study participants. Assurance given to the subjects that anonymity and confidentiality will be maintained.

\section{Data analysis:-}

The distribution of background variables was expressed as frequencies and percentage. The quality of life scores were expressed as mean with standard deviation. The association of quality of life scores with different variables were valuated using one- way ANOVA test.

\section{Results:-}

Mothers aged between 25 - 35 years were $76.7 \%$. With the regard to educational status $76.7 \%$ of mothers had higher secondary qualification. Regarding occupation $50.7 \%$ of mothers were employed. Regarding monthly income of $83.6 \%$ of mothers had below Rs. 2500 . With regard to type of family $84.9 \%$ of mothers were from Nuclear family. Regarding domicile $90.4 \%$ of the mothers were from the rural area. Regarding the diagnosis, $95.9 \%$ of the child had Acute Lymphoblastic Leukemia. Among 73 mothers, it revealed that the overall mean scores of life of mothers of children with leukemia was 77.03. The domain wise quality of life of mean scores showed that the physical domain ( 12.67 ), emotional domain ( 9.34 ), social domain ( 10.11 ), cognitive ( 8.73 ), communication domain ( 6.16 ), worry domain ( 10.27 ), daily activities ( 6.33 ), family relationship ( 10.97 ). There was no significant association between the quality of life of mothers of children with leukemia in relation to socio-demographic variables.

\section{Discussion:-}

The study findings revealed that the overall mean scores of quality of life of mothers of children with leukemia was 77.03. The supporting studies were as follows. Louise von Essen et al.30 conducted a study to assess the quality of life among Swedish mothers of children with cancer treatment. The findings of this study suggested that fathers experience a better quality of life than mothers. M Barrera, et al.33 conducted a study to examine longitudinally health - related quality of life ( HRQOL) of parents with leukemic children who undergo SCT ( stem cell transplant). The findings showed poor HRQOL for mothers and fathers.

\section{Conclusion:-}

The quality of life of mothers is a broad concept that incorporates the perceptions, illness experience of children and functional status related to children medical condition. Assessment of quality of life of mothers quantifies multiple factors which indirectly improve the quality of life of children who is suffering from leukemia. 


\section{References:-}

1. Kusumakumary. Rojimon Jacob. Profile of pediatric malignancies. Indian pediatrics. Vol 37- Nov 17; 2003; $1234-1237$.

2. Nandakumar Ambakumar, Anantha Narayanappa, Appaji L, Kumara swamy. Descriptive epidemiology of childhood cancers in Bangalore, India: cancer causes and control. Vol.7 No.4. July 1996 Pp: 405- 410.

3. C Eiser, J.R. Eiser. Health quality life outcomes 2005.April 28; 3:29.

4. E.A.Earie, S.A.Clarke, CEiser, L Sheppard. Child care health development 2007 March; 33 ( 2 ): 155- 60.

5. F Hashemi, N Asadi, N Beheshtipour, M Karimi. The impact of educating parents of leukemic children on the patient's quality of life Indian pediatrics Vol.13, August 2011.

6. Enskar K, Hamrin E, Carlsson M, von Essen 1. Swedish mothers and fathers of children with cancer : perceptions of well - being, social life, and quality care. J Psychosoc Oncol ( Internet ). $2011 ; 29 ; 52-66$. Available from:http:// www.ncbi.nlm.nih.gov/pubmed/21240725.

7. Barrera M, Atenafu E, Doyle J, Berlin - Romalis D, Hancock K. differences in mother's and father's health related quality of life after pediatric SCT : a longitudinal study. Bone Marrow Transplantation.2012.P.8559. 